\title{
UPAYA PELESTARIAN TARI TREBANG RANDU KENTIR PADA SANGGAR ASEM GEDE DESA MUNTUR KECAMATAN LOSARANG KABUPATEN INDRAMAYU-JAWA BARAT
}

\section{Oleh: Irayanti}

Pembimbing Tugas Akhir: Dra. Tutik Winarti, M.Hum dan Dra. Sri Hastuti, M.Hum Jurusan Tari, Fakultas Seni Pertunjukan, Institut Seni Indonesia Yogyakarta

E-mail: iraayu14@gmail.com

\begin{abstract}
RINGKASAN
Tari Trebang Randu Kentir merupakan pengembangan dari Kesenian Trebang yang diperkirakan telah berkembang cukup lama di Losarang. Kesenian Trebang telah akrab dengan kepercayaan animisme, nuansa kehinduan, hingga pengaruh dari agama Islam sekitar abad ke 17. Tari Trebang Randu Kentir mulai dikenalkan secara luas pada tahun 1970 oleh Cahya dengan mengangkat sebuah cerita rakyat tentang hanyutnya Nyi Dariwan di Sungai Cimanuk. Pada tahun 2009, Tari Trebang Randu Kentir diangkat kembali oleh Dede Jaelani dari Sanggar Asem Gede. Usaha yang dilakukan Dede Jaelani, sejalan dengan apa yang tengah pemerintah Indramayu lakukan mengenai program revitalisasi pada tahun 2011 dengan menghidupkan kembali kesenian daerah yakni Tari Trebang Randu Kentir agar dapat dilestarikan, dikelola dan dikembangkan.

Pendekatan yang digunakan yaitu ilmu sosiologi dan koreografi. Ilmu sosiologi diharapkan dapat membantu untuk mengetahui aktivitas dari Sanggar Asem Gede dan apresiasi masyarakat terhadap Tari Trebang Randu Kentir. Pendekatan koreografi digunakan untuk membedah aspek bentuk, teknik, isi serta pengembangan gerak dalam koreografi Tari Trebang Randu Kentir pada Sanggar Asem Gede.

Beberapa cara dan usaha pelestarian yang dilakukan Sanggar Asem Gede, yaitu mengembangkan bentuk, pembagian materi dan susunan gerak (SD, SMP, SMA/sederajat), pelatihan tari, dan sosialisasi. Tidak hanya Sanggar Asem Gede, pemerintah dan masyarakat secara tidak langsung diharapkan mampu mendukung dan menjaga Tari Trebang Randu Kentir agar masih bias dinikmati oleh generasi berikutnya.
\end{abstract}

Kata kunci: Pelestarian, Tari Trebang Randu Kentir, Sanggar Asem Gede 


\section{ABSTRACT}

Trebang Randu Kentir dance is a development of Trebang Arts which is estimated to have developed long enough in Losarang. Art Trebang has been familiar with the beliefs of animism, nuances of hinduism, until the influence of Islam around the 17th century. Trebang Randu Kentir dance became widely known in 1970 by Cahya. Cahya developed Trebang Randu Kentir dance by raising a folklore about the drift Nyi Dariwan in Cimanuk river. In 2009, Trebang Randu Kentir Dance was reappointed by Dede Jaelani with his dance studio, that's dance studio Asem Gede, with the aim to channel the public interest to Trebang Randu Kentir dance. Dede Jaelani's efforts are in harmony with what the Government of Indramayu is doing about the revitalization program in 2011 by reviving the local arts of Trebang Randu Kentir Dance in order to be preserved, managed and developed.

The approach used is the science of sociology and choreography. The science of sociology is expected to help to know the activities of dance studio of Asem Gede and the public appreciation of the Trebang Dance Randu Kentir. The choreography approach is used to dissect aspects of form, technique, content and development of motion in choreography Trebang Randu Kentir dance at dance studio Asem Gede.

Several ways and conservation efforts are done by dance studioof Asem Gede, which is developing the form, the distribution of materials and the composition of motion (elementary scchool, junior high school, high school or on an equal), dance training, and socialization. Not only dance studio of Asem Gede, government and society are indirectly expected to be able to support and maintain Trebang Randu Kentir dance to still be enjoyed by the next generation.

Keywords: Preservation, Trebang Randu Kentir dance, dance studio of Asem Gede

\section{PENDAHULUAN}

Kesenian Trebang merupakan seni tetabuhan yang memiliki sajian tarian yang tidak terstuktur (belum ada komposisi). Kesenian Trebang diperkirakan sudah ada sejak lama dengan adanya pengaruh dari animisme, nuansa kehinduan dan lain sebagainya. Tidak hanya nuansa kehinduan yang ada di dalamnya, tetapi pengaruh dari beberapa tokoh penyiar agama Islam yang memasuki Indramayu yaitu Ki Kuwu Sangkan, tampaknya menjadi nilai tambah pada tampilan yang khas dari Kesenian Trebang. 
JOGED

ISSN: $1858-3989$
Irayanti (UPAYA PELESTARIAN TARI TREBANG RANDU KENTIR PADA SANGGAR ASEM GEDE DESA MUNTUR KECAMATAN LOSARANG KABUPATEN INDRAMAYU-JAWA BARAT)
Fenomena selanjutnya Kesenian Trebang dikembangkan oleh seniman Losarang yakni Cahya selaku dalang (mahir menari dan menabuh gamelan: dalam bahasa Indramayu) pada Grup Kesenian Trebang "Randu Kentir". Cahya mengemas Kesenian Trebang menjadi sebuah tarian yang utuh. Adapun Cahya sebagai seniman yang memiliki jiwa kreativitasnya, menggarap gerak ciptaannya berdasarkan hasil pengamatan terhadap kondisi alam, geografis, cerita rakyat dan juga hasil belajar dengan seniman Tari Topeng Carpan. Dede Jaelani menuturkan bahwa:

Cahya mengangkat sebuah cerita rakyat mengenai hanyutnya Nyi Dariwan di Sungai Cimanuk. Cerita tersebut bermula ketika Nyi Dariwan mengambil beberapa batang pohon randu dengan menyarah (mengambil dengan menggunakan weteng atau galah) yang terhanyut di sungai. Pada masa itu tampaknya cuaca tidak bersahabat, yakni hujan deras yang mengakibatkan meluapnya air sungai Cimanuk, hingga akhirnya Nyi Dariwan terhanyut karena tidak dapat menahan luapan Sungai Cimanuk.

( Dede Jaelani, 17 Maret 2017 di Sanggar Asem Gede)

Keberadaan Tari Trebang Randu Kentir mendekati masa kritis pada tahun 1980, hingga Cahya meninggal pada tahun 2009. Sepeninggal Cahya, tampaknya memicu kesadaran yang tumbuh pada anak perempuan dari pemimpin Grup Kesenian Trebang "Randu Kentir" yaitu Ida untuk memegang kembali warisan tari rakyat yang ditanamkan oleh Cahya. Pada tahun tersebut juga salah satu murid Carpan dan Cahya yakni Dede Jaelani memulai tindakan kepeduliannya terhadap keberadaanTari Trebang Randu Kentir dengan mendirikan sebuah sanggar seni yang diberi nama Sanggar Asem Gede yang berada di desa Muntur kecamatan Losarang kabupaten Indramayu-Jawa Barat.

Kondisi dari kedua sanggar tersebut yang tengah melakukan suatu tindakan pelestarian terhadap Tari Trebang Randu Kentir, yang belum mendapat simpati dari masyarakat, memicu kepedulian pemerintah Indramayu yang saat itu tengah mengadakan sebuah program untuk dapat mensehajterahkan masyarakat dengan keseniannya. Tampaknya, program pemerintah Indramayu tersebut segandeng dan satu tujuan dengan apa yang Ida dan Dede Jaelani geluti Akhirnya, pemerintah Indramayu bekerjasama dengan seniman-seniman Indramayu, sanggar-sanggar seni dan juga beberapa lembaga daerah (Dinas Pemuda Olahraga Kebudayaan dan Pariwisata) mengadakan sebuah program revitalisasi terhadap tari rakyat Indramayu (khususnya Tari Trebang Randu Kentir) pada tahun 2011 dengan dihadiri oleh Panitia Balai Pelatihan Taman Budaya Bandung berlokasi di kecamatan Losarang.

Revitalisasi berasal dari kata re memiliki arti kembali dan vital memiliki arti 
hidup atau sangat penting. (Hasan Alwi, 2005:936 \& 1262). Menurut Endang Caturwati:

Revitalisasi adalah usaha untuk mem-vital-kan atau menghidupkan sesuatu yang eksistensinya masih berarti sehingga perlu dijaga dan dikembangkan. (Sri Rustiyanti, editor Endang Caturwati, 2010:22)

Puncak program revitalisasi tersebut yaitu tarian yang telah digarap kemudian di sebarkan dengan cara pelatihan, didiskusikan serta dipentaskan sebagai sajian ragam gerak pada Tari Trebang Randu Kentir. Hasil dari pementasan tersebut berpengaruh pada pemahaman masyarakat mengenai sanggar seni yang ditinjau yakni Grup Kesenian Trebang "Randu Kentir" dan Sanggar Asem Gede. Tujuannya agar dapat meningkatkan kualitas serta keseriusan sanggar dalam menjaga dan melestarikan tari rakyat asal Losarang.

II. PEMBAHASAN

\section{A. Bentuk Penyajian Tari Trebang Randu Kentir Pada Sanggar Asem Gede}

cara

Pengertian penyajian adalah menghidangkan wujud itu agar dapat dinikmati oleh penonton. Pengertian penyajian dalam bentuk tari merupakan wujud yang terdapat dalam penampilan suatu bentuk tari yang terdiri atas komponen-komponen yaitu tema, gerak tari, iringan tari, properti tari, jumlah penari, tata rias dan busana, waktu dan tempat, pola lantai yang merupakan satu kesatuan dalam penyajian tari sehingga tari dapat dinikmati.

( Jacquelin Smith. 1976. Diterjemahkan oleh Ben Suharto, 1985:6)

\section{Tema Tari}

Tema merupakan bagian terpenting dalam penggarapan suatu karya. Melalui tema yang digarap, komposisi tari dapat dibedakan menjadi dua tema, yaitu tema literal dan tema non literal. Tema literal adalah komposisi tari yang digarap dengan tujuan tertentu untuk menyampaikan pesan-pesan, seperti dongeng, legenda, sejarah dan pengalaman pribadi. Tema non literal adalah komposisi tari yang digarap berdasarkan pengelompokan dan penggarapan keindahan unsur-unsur gerak, ruang, waktu dan tenaga. (Sal Murgiyanto, 1986:22). Mengenai paparan tema diatas, dapat diambil suatu penjabaran mengenai tema tari yang ada di Tari Trebang Randu Kentir yang tergolong ke dalam tema literal, yakni komposisi tari yang mengangkat sebuah dongeng maupun cerita rakyat Losarang ke dalam sebuah sajian pertunjukannya.

\section{Unsur Sikap dan Gerak}

Unsur sikap dan gerak menghasilkan sebuah gaya pada sebuah tari. Gaya atau style dalam pemahaman ini lebih mengarah pada bentuk ciri khas atau corak yang terdapat pada gaya gerakan dalam komposisi tari atau bentuk koreografi, terutama menyangkut pembawaan pribadi atau individual, kelompok maupun ciri kespesifikasikan dari sosial budaya 
JOGED

ISSN: $1858-3989$
Irayanti (UPAYA PELESTARIAN TARI TREBANG RANDU KENTIR PADA SANGGAR ASEM GEDE DESA MUNTUR KECAMATAN LOSARANG KABUPATEN INDRAMAYU-JAWA BARAT) tertentu yang melatarbelakangi kehadiran koreografi sebagai bentuk.

(Y. Sumaniyo Hadi, 2014:53)

Adapun kehadiran gaya yang terdapat pada Tari Trebang Randu Kentir berkaitan dengan latar belakang budaya dan letak geografis daerah asalnya atau disebut dengan gaya emblem. Menurut Sumaryono dikatakan bahwa, gaya emblem adalah suatu ungkapan sebagai ungkapan "inilah kami” yang merujuk pada geografi budaya sebagai identitasnya.(Sumaryono, 2011:75).

Hal lain juga muncul pada sistem mata pencaharian yang ada di Indramayu, sebagian masyarakat merujuk pada beberapa macam garis besar pekerjaan, yakni sebagai petani, peternak, nelayan, pedagang dan sebagainya. Hasilnya, menunjukan bahwa hubungan antar masyarakat dengan hasil kekayaan alam bawah tanah terlihat sangat akrab dan erat. Salah satu contohnya yakni pada nama motif gerak urang unggut dan bebek ngoyor.

Nama urang unggut merujuk pada pemahaman masyarakat Indramayu sebagai hasil kekayaan hewan yakni urang/ udang yang berada pada empang, sungai maupun laut. Istilah bebek ngoyor dari kata bebek yang merupakan gambaran dari hewan yang berada di sungai atau kali maupun empang, kemudian ngoyor jika diartikan ke dalam bahasa Indonesia yaitu berenang di dalam air. Hal tersebut merupakan salah satu gambaran keadaan hewan di sungai maupun empang yang masih menjadi mata pencaharian sebagian masyarakat Losarang.

Pengaruh adanya mata pencaharian dalam bidang bercocok tanah atau atau bertani terlihat pada ide garap yang diciptakan Cahya, yakni dengan melihat salah seorang warga ketika memanen padi dengan cara mengais ${ }^{l}$. Hal lain juga tampak menunjukkan bahwa pada gerak serogan tersebut merupakan penggambaran sosok Ki Dariwan yang tengah berusaha menolong istrinya yang hanyut di sungai.

\section{Properti Tari}

Pada Tari Trebang Randu Kentir, properti yang digunakan yaitu sumping atau rawis. Rawis atau sumping dalam pemahaman para seniman Indramayu, diartikan sebagai benda yang berbentuk bulat yang berbahan manik-manik kecil (seperti butir tasbih) dengan ditambah aksesoris bros berbentuk bunga dan ditambahkan juga hasil olahan benang-benang woll yang dibentuk memanjang pada ujungnya. Penggunaan sumping didasari karena memiliki nilai dan tujuan tertentu. Nilai dan tujuan tersebut yaitu mengingatkan masyarakat Indramayu agar selalu menjungjung tinggi rasa syukur atas limpahan karunia yang telah diberikan Tuhan Yang Maha Esa.

1 Mengais dalam pemahaman masyarakat Indramayu merupakan suatu kegiatan memanen padi dengan beberapa tahapan. Tahapannya yaitu padi diambil dengan arit (sabit) kemudian dipisahkan, padipadi yang telah dipisahkan kemudian di gebod 


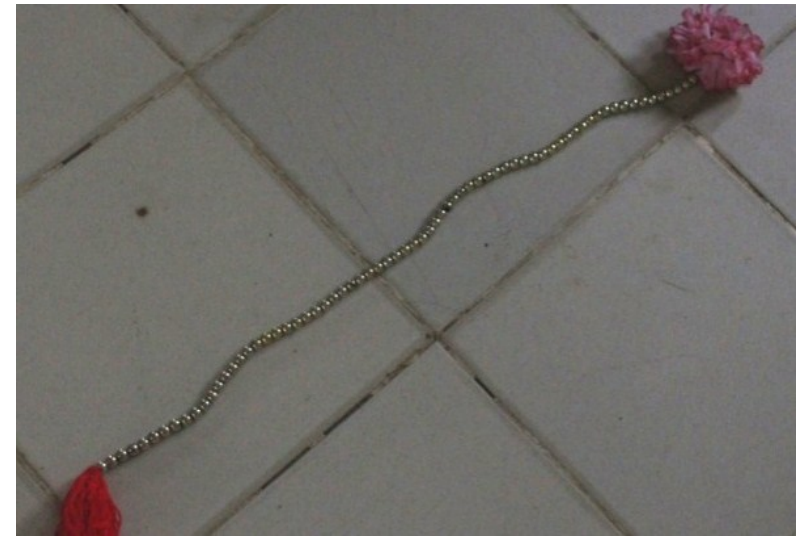

Gambar 1: Sumping atau rawis properti Tari Trebang Randu Kentir. (Foto: Irayanti, di Losarang 2017)

\section{Iringan Tari}

Iringan tari merupakan lagu yang dihasilkan dari beberapa proses pembentukan dan penyeleksian gerak yang berhubungan dengan instrumen tarinya. (Y. Sumandiyo, 2014:115). Beberapa instrumen Tari Trebang Randu Kentir yaitu:

- Trebang, terebang/ blangber, berfungsi sebagai mempertegas tekanan penuh pada akhir kalimat lagu tarinya, yakni sebagai pengganti goong.

- Truntung, berfungsi sebagai kempul atau memperkuat ritme kendang, memberi ketebalan dinamika kendang dan saling mengisi dengan ritme tabuhan klenang.

- Kendang, berfungsi untuk mengatur keseluruhan irama tari, mengatur dinamika dan memperkuat ketebalan setiap gerak.

- Klenang, berfungsi untuk mengatur ritme lagu atau mengatur ketetapan ritme.

- Kecrek, berfungsi sebagai aksentuasi terhadapa tekanan gerak dari mempertajam kekuatan tepak kendang.

\section{Tempat Pertunjukan}

Tempat pertunjukan pada Tari Trebang

Randu Kentir biasanya dapat dilakukan dimana saja dan kapan saja, sesuai keinginan penanggap. Misalnya pada gedung-gedung pertunjukan seperti proscenium stage, pendhapa, balai desa, alun-alun maupun tanah lapang.

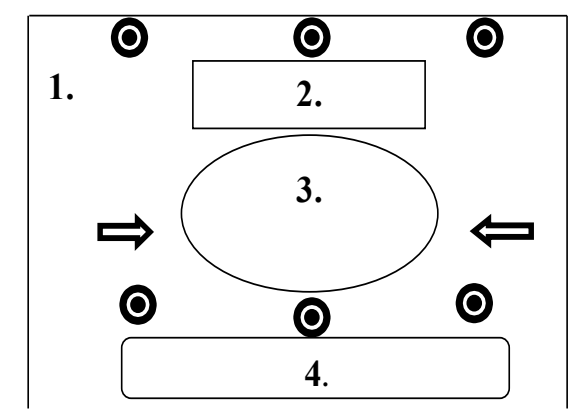

Gambar 2: Skema model tata letak ruang dan panggung pertunjukan Tari Trebang Randu Kentir di area Sekolah Dasar Krimun 2, Losarang-Indramayu.

\section{Keterangan:}

1. Area pertunjukan di tanah lapang yang dibatasi saka/ pembatas

2. Area panjak/ para penabuh

3. Area penari untuk menari

4. Area penonton
$\Longrightarrow$ Arah keluar dan masuk penari
( Saka/ garis pembatas antara penonton dan penari

\section{Rias dan Busana}

Tata rias yang digunakan pada Tari Trebang Randu Kentir menunjukkan aura kesederhanaan riasannya, yakni menggunakan rias cantik dengan mempertajam bagian mata. Berikut ini beberapa unsur-unsur yang ada pada busana Tari Trebang Randu Kentir yang dikenakan penari. Terdiri dari busana bagian atas dan busana bagian bawah. Yaitu: 
a. Busana bagian atas: Klambi dalam bahasa Indramayu diartikan sebagai baju. Klambi tersebut memiliki warna-warna mencolok seperti merah, biru, pink, ungu, kuning dan peach.

b. Busana bagian bawah: Tapih dalam bahasa Indramayu berarti kain batik.( Warnali, Tatang Sutandi, Sulistijo, dkk, 2011:117). Motif tapih yang digunakan dalam Tari Trebang Randu Kentir, yaitu jenis motif rajeg wesi, motif genggeng dan kembang jeruk.

c. Busana pelengkap:

- Ikat kepala yang pada pemahaman masyarakat Indramayu disebut iket wulung. Iket wulung yaitu kain batik yang dibentuk segitiga dengan diselipkan lidi pada ujung bagian depan.

- Krodong, yaitu kain yang berbahan batik yang menutupi bagian dada.

- Selendang atau sampur.

- Rawis atau sumping dalam pemahaman masyarakat Indramayu, yaitu sebuah properti atau benda yang melekat pada penari yang berbentuk memanjang terbuat dari manik-manik berbentuk bulat kecil-kecil (seperti butiran tasbih) dan dipercantik dengan bros yang berbentuk bunga serta ditambah untaian benang woll yang dibentuk memanjang pada ujung sumping.

- Benting atau sabuk, yakni sebuah kain yang berbahan satten dengan berwarna terang (kuning, biru, dan lain lain) yang sudah di buat seperti bentuk sabuk danpakai di bagian pinggang.

- Korset, dipahami oleh masyarakat Indramayu sebagai benda berbahan kain yang lengket atau perekat, korset bertujuan mengeratkan baju dan kain atau memperkecang antar baju dan kain agar menjadi rapih dan tidak mudah lepas.

- Dasi (berbentuk seperti huruf Y yang berbahan sateen dan berwarna merah marun). Dasi digunakan hanya untuk penari yang menari dibagian awal (manji) pada Tari Trebang Randu Kentir pada tingkat SMA/sederajat. 


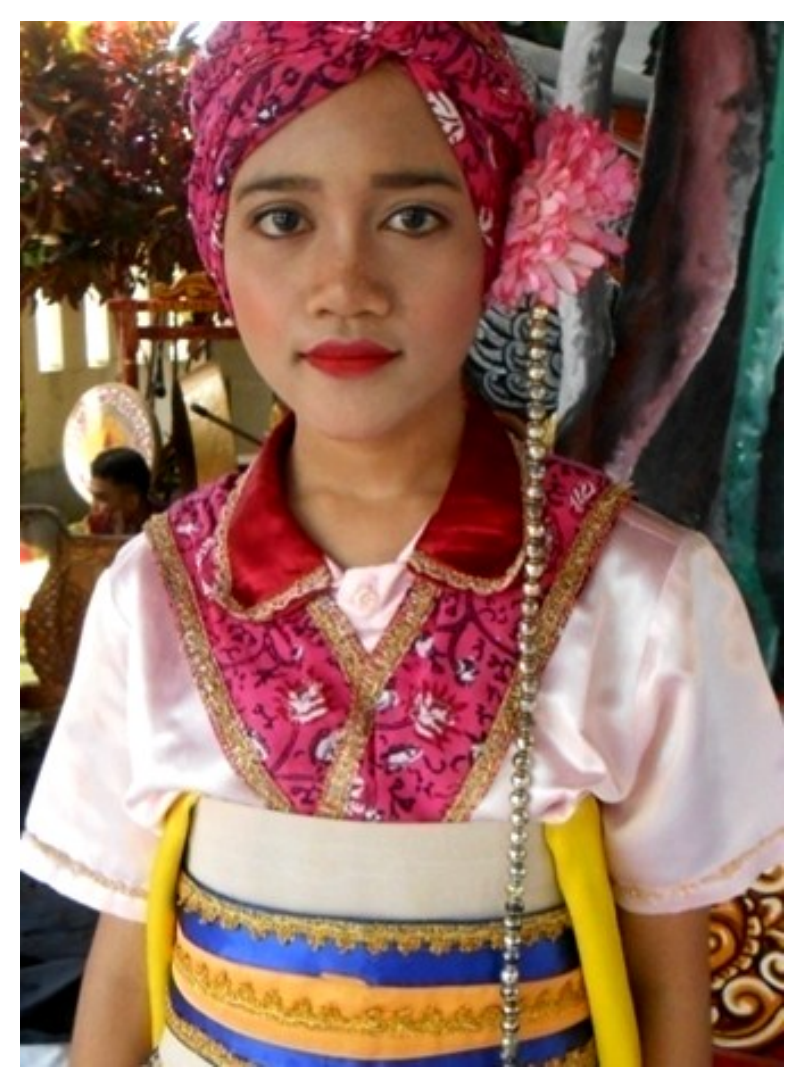

Gambar 3: Rias dan busana penari Tari Trebang Randu Kentir. (Foto: Irayanti, 2017 di Losarang)

\section{Pola Lantai}

Pola lantai Tari Trebang Randu Kentir

pada Sanggar Asem Gede umumnya disesuaikan dengan jumlah penari dan keadaan tempat pertunjukannya, misalnya kerucut terbalik (lima penari), lingkaran, selang seling, berbanjar, berbaris dan lain sebagainya.

\section{B. Nilai Pada Tari Trebang Randu}

\section{Kentir}

Pada dasarnya nilai dapat ditemukan diberbagai wujud dan bentuk yang tampak secara kasat mata, baik dalam wujud benda-benda, naskah atau tulisan, artifak maupun juga kesenian. Nilai juga terkait dengan konteks dan latar belakang historis dari wujud fisik tersebut.(Heri Herdiani, Suhendi Afryanto, Endah Irawan, dkk, 2008:7).
Menurut Woods nilai dibedakan menjadi empat jenis, diantaranya yaitu: (http://perpustakaancyber.blogspot.co.id/2013/ 05/pengertian-nilai-dan-norma-sosial-diMasyarakat.html diakses pada tanggal 10 April 2017).

\section{a. Nilai Etika}

Nilai etika ialah nilai untuk manusia sebagai pribadi yang utuh, misalnya kejujuran. Nilai tersebut sangat berhubungan dengan akhlak. Nilai ini juga berkaitan dengan benar dan salah yang dianut oleh golongan atau masyarakat. Nilai etika sering disebut sebagai nilai moral, akhlak atau budi pekerti.

\section{b. Nilai Estetika}

Nilai estetika memiliki tujuan penilaian untuk menentukan keindahan, yakni berhubungan dengan hal-hal yang bagus atau jelek. Nilai estetika atau nilai keindahan sering dikaitan dengan benda, orang dan peristiwa yang bisa menyenangkan hati (perasaan). Nilai estetika juga dikaitkan dengan karya seni, walaupun sebenarnya semua ciptaan Tuhan juga mempunyai keindahan alami yang tidak tertandingi. Nilai estetika juga dikaitkan dengan sifat atau perangai manusia seperti tindak-tanduk dan tutur kata seseorang.

\section{c. Nilai Agama (Religi)}

Nilai agama berkaitan dengan menilai hubungan manusia dengan Tuhan, yaitu melakukan perintah dan meninggalkan 
JOGED

ISSN: $1858-3989$
Irayanti (UPAYA PELESTARIAN TARI TREBANG RANDU KENTIR PADA SANGGAR ASEM GEDE DESA MUNTUR KECAMATAN LOSARANG KABUPATEN INDRAMAYU-JAWA BARAT) larangan-nya. Nilai agama berkaitan dengan ajaran Tuhan Yang Maha Esa dalam agamaagama. Nilai agama diwujudkan dalam bentuk amal perbuatan sebagai ibadah kepada Tuhan Yang Maha Esa.

\section{d. Nilai Sosial}

Nilai sosial merupakan suatu penilaian untuk menentukan kualitas hubungan antar manusia dalam pergaulan hidupnya. Nilai sosial berkaitan dengan perhatian dan perlakuan kita terhadap sesama manusia di lingkungan. Nilai sosial tewujud karena manusia sebagai makhluk sosial. Manusia harus menjaga hubungan diantara sesamanya, hubungan ini akan menciptakan sebuah keharmonisan dan sikap saling membantu

Dari paparan mengenai penjelasan jenis-jenis nilai, maka jika dilihat dari bentuk koreografiTari Trebang Randu Kentir yang tampak dari dalam dan luar, tampaknya memiliki beberapa unsur nilai tertentu, berikut ini merupakan paparannya:

1) Penggunaan sumping atau rawis

Sumping atau rawis yang melekat pada kepala penari, tercermin sebagai salah satu benda atau yang alat yang digunakan masyarakat pemeluk Islam ketika melakukan dzikir, yakni seperti bentuk tasbih.

(Karna pada tanggal 19 Maret 2017 di desa Santing, Losarang-Indramayu).

Tampaknya, nilai agama yang ada pada

Tari Trebang Randu Kentir memiliki hubungan antara agama Islam dengan masyarakat, yakni sudah menjadi salah satu pegangan atau ajaran yang diterima dengan baik oleh masyarakat Indramayu. Hal tersebut terbukti bahwa hampir seluruh penduduk desa yang ada di Indramayu, mayoritas masyarakatnya memeluk agama Islam.

2) Sikap dan gerak

a. Manji

Berdasarkan pengamatan peneliti, bahwa sikap penari yang membelakangi penonton pada Tari Trebang Randu Kentir selain sebagai penghormatan kepada Tuhan dan leluhur, tampaknya sikap tersebut mendapat pengaruh pada Tari Topeng yang terlebih dahulu menjadi tarian yang ada di Indramayu dan Cirebon. Pada pertunjukan sebelum Tari Topeng dimulai, sikap penari selalu membelakangi penonton sembari duduk dan berdoa. Sikap tersebut selain memiliki nilai agama yang berfungsi sebagai penghormatan terhadap Tuhan dan leluhur, tampaknya secara tidak langsung gambaran nilai etika terlihat masuk pada sikap tersebut.

Manji merupakan singkatan dari pasang panji, yakni salah satu unsur sikap pada Tari Topeng Panji gaya Carpan (Achmad Hidayat, Abdul Aziz, Dindin Rasidin, dkk, 1992:36). Tampaknya pengaruh tersebut memberikan ide garap Cahya dalam mengolah gerak dengan proses stilisasi (penghalusan) gerak yang lebih kreatif, hingga dinamakan motif gerak manji. Pada sikap tangan penari melakukan gerak 
manji, terlihat pada sikap jari tangan kanan penari seperti menunjuk ke atas, bahwa sikap tersebut mencerminkan bahwa masyarakat Indramayu khususnya Losarang, sebagian warganya menganut kepercayaan Islam.

\section{b. Serogan}

“... gerak serogan menggambarkan sikap $\mathrm{Ki}$ Dariwan ketika menolong Nyi Dariwan dengan membuka kedua tanggannya, tetapi karena arus sungai Cimanuk yang meluap, akhirnya nyawa Nyi Dariwan tidak mampu diselamatkan." (Dwi Septiani K.Wulandari (31 Desember 2015) di Indramayu dan Dede Jaelani (29 April 2016) di Isi Surakarta.)

Penuturan narasumber tersebut terlihat bahwa gerak serogan tergolong dalam salah satu bagian nilai yang dijelaskan Woods, yaitu mengenai nilai sosial. Artinya, nilai sosial tersebut mencerminkan sikap dan perilaku antar sesama. Nilai sosial lain juga muncul secara tidak langsung pada proses menggerakkan gerak serogan. Hal tersebut dijelaskan oleh Dede Jaelani bahwa proses gerak serogan diilhami dari gerak seorang petani yang tengah mengais atau membersihkan padi dengan alat arit (sabit). Tampaknya, Cahya memvisualisasikan gerak petani tersebut, kemudian menggarapnya ke gerak yang sudah distilisasi atau diperindah. Tujuannya agar mengingatkan bahwa hasil kekayaan alam Indramyu pada sektor pertanian merupakan tempat yang subur dan memberi manfaat pada masyarakat dalam memperoleh rejeki untuk memenuhi kebutuhannya.

\section{Profil Sanggar Asem Gede}

Pada tahun 2005 sampai menginjak ke 2009, kesabarannya belajar kesenian "tari" Topeng gaya Carpan dan Trebang milik Cahya membuahkan hasil. Dede Jaelani lambat laun mengerti dan memahami apa saja nilai ataupun pesan yang ada pada Tari Trebang Randu Kentir yang hampir mirip dengan sajian pertunjukan Topeng gaya Carpan. Pada tahun 2009 sanggar seni rintisannya tersebut lahir dengan nama "Sangga Asem Gede" yang memiliki tujuan untuk merintis dan melestarikan Tari Trebang Randu Kentir dan Tari Topeng gaya Carpan.

D.UPAYA DAN HASIL PELESTARIAN TARI TREBANG RANDU KENTIR PADA SANGGAR ASEM GEDE

\section{Upaya Pelestarian Tari Trebang Randu Kentir}

Pelestarian sebenarnya merupakan usaha fikiran dan tindakan yang berupa kegiatan atau aktivitas seseorang dalam melakukan sesuatu dengan caranya sendiri tanpa meninggalkan ciri khas sesuatu. Upaya melestarikan sesuatu dalam hal ini tari merupakan penanganan khusus. Artinya dibutuhkan pemikiran yang matang dan terarah, sehingga warisan budaya yang adiluhung tetap terlestari. Adapun tari yang dilestarikan perlu adanya inovasi atau ciptaan- 
JOGED

ISSN: $1858-3989$

Irayanti (UPAYA PELESTARIAN TARI TREBANG RANDU KENTIR PADA SANGGAR ASEM GEDE DESA MUNTUR KECAMATAN LOSARANG KABUPATEN INDRAMAYU-JAWA BARAT)

ciptaan baru yang lebih mengundang apresiasi dari masyarakatnya (Edi Sedyawati, 1981:51)

Kehadiran Tari Trebang Randu Kentir yang telah mengalami beberapa fase perjalanan, hingga akhirnya dikembangkan dengan seniman yang menggelutinya. Ketika puncaknya Tari Trebang Randu Kentir direvitalisasi oleh pemerintah Indramayu pada tahun 2011 agar tari tersebut dapat mengangkat kembali seni budaya di Indramayu beserta mensejahterahkan masyarakat yang sebagai penikmat dan pengamat seni. Tidah hanya itu, tujuan lain yaitu agar produk kesenian Indramayu yakni Tari Trebang Randu Kentir, agar dapat dilestarikan, dikelola dan dikembangkan dengan pegiat seni dengan caranya masingmasing.

Fenomena selanjutnya, menunjukkan bahwa diantara sanggar-sanggar yang melestarikan, mengelola maupun mengembangkan Tari Trebang Randu Kentir tersebut, tampaknya hanya Sanggar Asem Gede yang melalukan pengelolaan berupa pengajaran Tari Trebang Randu Kentir dengan teratur. Sanggar Asem Gede merupakan salah satu sanggar seni yang berasal dari desa Muntur, Losarang yang bergerak dalam bidang tari.

2. Pelaku Upaya Pelestarian Tari Trebang Randu Kentir

\section{1) Pemerintah Indramayu}

Peran pemerintah mengenai dukungan untuk sanggar-sanggar tersebut tercermin dengan adanya beberapa macam acara maupun festival yang digelar dengan melibatkan sanggar-sanggar seni yang ada di Indramayu. Salah satunya yaitu, mengundang Sanggar Asem Gede dalam acara Hari Ulang Tahun Indramayu hampir setiap tahun. Bukan hanya sebatas mengundang, tetapi juga pemerintah sebaiknya mengadakan bantuan secara langsung, yaitu berupa uluran dana untuk memfasilitasi sarana maupun prasarana pada sanggar seni, khususnya Sanggar Asem Gede agar terjalin proses pelestarian yang diharapkan.

\section{2) Masyarakat}

Di bawah ini merupakan uraian acaraacara desa yang ada di desa Muntur yang masih menghadirkan Tari Trebang Randu Kentir sebagai acara hiburan dan sekaligus sebagai media sosialisasi Sanggar Asem Gede kepada masayarakat, yaitu:

\section{a. Ngunjung di Kebuyutan Gentong}

Ngunjung merupakan salah satu kegiatan yang dilakukan masyarakat untuk mengunjungi makam para leluhur atau pendiri desa. Pada puncak pelaksanaan ngunjung juga di hadirkan sajian pertunjukan rakyat yang ada di Indramayu, salah satunya di pentaskan pertunjukan tari-tarian asal Losarang yaitu Tari Trebang Randu Kentir. 


\section{b. Hajatan}

Melalui hajatan dapat mempererat tali silaturahmi antar warga. Tampaknya, melalui Hajatan yang digelar salah seorang warga, secara tidak langsung memiliki tujuan dan manfaat bagi kedua belah pihak. Manfaat untuk masyarakat yaitu, sebagian masyarakat yang ikut hadir pada hajatan merasa terhibur dengan sajian pertunjukan yang digelar oleh pemilik hajat, dan di sisi lain tamu (warga masyarakat) dapat mengetahui keberagaman tarian daerah khas Losarang. Adapaun manfaat bagi Sanggar Asem Gede yaitu sebagai salah satu cara mengenalkan Tari Trebang Randu Kentir agar dikenal secara luas lagi.

\section{E. Upaya Pelestarian Yang Dilakukan Sanggar Asem Gede}

\section{Pengembangan Bentuk}

\section{a. Pengembangan Busana}

Busana Tari Trebang Randu Kentir pada jaman dahulu, umumnya sangat sederhana. Yakni, pada bagian busana atas yang disebut klambi yang dikenakan berwarna biru tua dan terbuat dari batik paoman.(Achmad Hidayat, Dindin Rasidin, Ella Nurlaelaningsih, dkk, 1992:65)

Untuk itu, karena terkesan sederhana dengan klambi yang berbahan kain batik yang serupa dengan bahan kain dengan tapih, maka klambi tersebut dikembangkan menjadi sesuatu yang berbeda

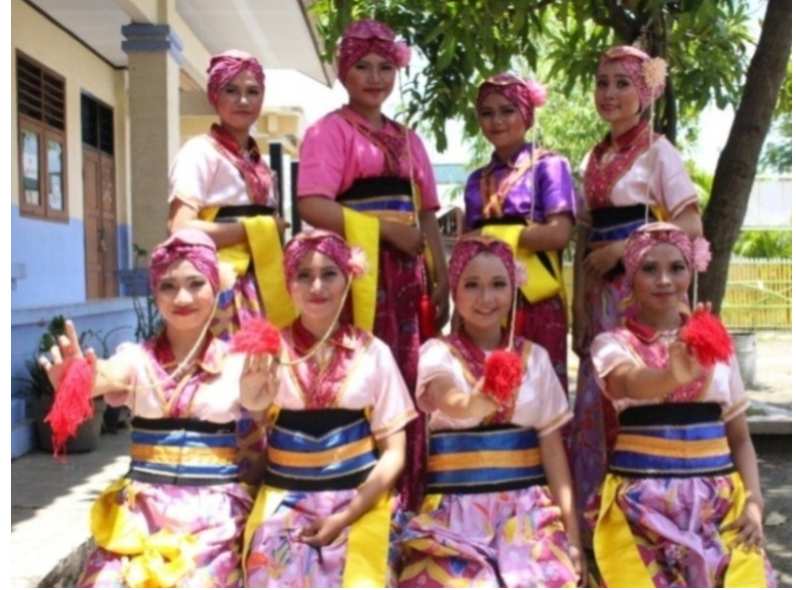

Gambar 4: Berbagai macam warna klambi pada anggota Sanggar Asem Gede. (Foto: Irayanti, 2017 di Losarang)

\section{b. Pengembangan Sumping}

Tari Trebang Randu Kentir pada jaman dahulu (Ciptaan Cahya) memiliki sumping yang serupa dengan sumping pada Tari Topeng Mama Carpa. Hal tersebut karena melihat penggunaan sumping yang hampir mirip, tampaknya membuat Sanggar Asem Gede berkeinginan untuk mengembangkan sumping dengan bahan yang berbeda. Tujuannya agar lebih memperindah bentuk sumping yang akan dikenakan.

\section{c. Pemendekan Durasi Pertunjukan}

Setelah program revitalisasi tahun 2011, sajian durasi pertunjukannya dipadatkan menjadi kurang lebih 10-15 menit yang bertujuan agar mempermudah proses pembelajaran pada sekolah-sekolah. Dede Jaelani membagi durasi waktu yang beragam untuk diajarkan pada anak-anak tingkat Sekolah Dasar (SD), Sekolah Menengah Pertama (SMP), Sekolah Menengah Atas 
(SMA). Misalnya, untuk anak-anak SD durasinya sekitar 5 menit, untuk SMP durasinya sekitar 12 menit dan untuk SMA/sederajat durasinya kurang lebih 15 menit.

2. Pembagian Materi dan Susunan Gerak

\section{1) Materi dan susunan Gerak Tingkat Sekolah Dasar (SD)}

Susunan penyajiannya dibagi menjadi 2 pembagian, bagian isi dan akhir dengan tidak menghadirkan tokoh (bagian awal/ manji).

a. Bagian Isi

Susunan geraknya yaitu: moyeg, joged miring, pasang dalung, pasang dalung ayun tangan, lontangan, dan serogan.

b. Bagian Akhir (deder)

dederan, tunggak kebanjiran, urang unggut, dan gerak yang menjadi sendi adalah gerak selagan.

\section{2) Materi dan Urutan Gerak Tingkat Sekolah Menengah Pertama (SMP)}

Sajian penyajiannya terlebih dahulu digelarkan tatalu (iringan musik pembukaan tari) yang berdurasi kurang lebih 30 detik.

a. Bagian Awal (manji; penari tunggal yang menari) Manji sebagai ragam gerak pokok. Motifmotif tersebut yaitu: dolanan sumping, tangan kanan nuduh, olah bahu dan tangan, dan dolanan selendang, jogged miring 1 , dan dolanan sumping.

b. Bagian Isi (penari menari secara rampak)

Pada bagian ini, semua gerak yang ditarikan merupakan motif yang terdiri dari: moyeg, joged miring 2, pasang dalung, lontangan 1, Lontangan 2, dan serogan.

c. Bagian Akhir (deder)

Susunan geraknya yaitu: dederan, tunggak kebanjiran, urang unggut, randa ngawe, bebek ngoyor, jintok-jintok, dan ngeleler selendang.

3) Materi dan Urutan Gerak Tingkat Sekolah Menengah Atas (SMA) atau sederajat.

Penyajiannya yaitu dengan menambahkan syair tembang Islam berupa shalawatan yang ada pada agama Islam yang dibawa Ki Kuwu Sangkan. Contoh syairnya berbunyi: shali'alaa...laa.. Tampaknya, hal tersebut menjadi sesuatu yang dikemas lebih berbeda oleh Dede Jaelani agar menjadi suatu sajian pertunjukan yang menarik. Berikut ini merupakan susunan gerak yang ada pada Tari Trebang Randu Kentir tingkat SMA/sederajat. Dimulai dengan tatalu sekitar kurang lebih 30 detik.

a. Bagian Awal (manji; penari tunggal) 
Motif gerak yang ada pada manji yaitu: dolanan sumping, tangan kanan nuduh, olah bahu dan tangan, dan dolanan selendang, joged miring I (bergerak mengelilingi area pementasan dengan permainan ayunan tangan kanan), dan dolanan sumping.

b. Bagian Isi (penari rampak) Moyeg, joged miring 2 (gerak membentuk lingkaran dengan permainan bolak-balik kedua jari-jari dan pergelangan tangan), pasang dalung 1(yakni gerakannya ditambah variasi obah bahu pada penari tengah. Sikap tangan penari tengah mengepal yang kedua tangan kepalan itu disimpan di dada, kemudian penari lainnya melakukan permainan pergelangan tangan kanan), pasang dalung 2 (sama seperti pasang dalung 1, hanya menekankan pada permainan sumping. Pada penari tengah dan penari lainnya melakukan variasi gerak obah bahu dan permainan pergelangan tangan kanan), lontangan 1, lontangan 2, dan serogan. c. Bagian Akhir (deder)

Susunan geraknya yaitu: dederan, tunggak kebanjiran, urang unggut, randa ngawe, bebek ngoyor, jintok-jintok, ipukan 1 selendang, ipukan 2 selendang, ngeleler sumping, ngeleler selendang, moyeg sungkem atau sembah.

\section{Pelatihan Tari}

Pelatihan menurut Bosker adalah suatu kegiatan pembelajaran yang terpogram dengan tujuan untuk meningkatkan kemampuan dan ketrampilan. (Bosker (1997) dalam Jurnal Pendidikan dan kebudayaan oleh Khairil Anwarnotodipuro vol. 19. No 1 maret 2013. ISSN 0215-2673)

Pelatihan tari disini dimaksudkan sebagai kegiatan dalam mempelajari bidang tertentu tanpa harus menghilangkan yang materi yang ada. Hal ini terkait dengan usaha Sanggar Asem Gede memiliki beberapa pelatih yang diharapkan mampu memberikan pelatihan yang baik dan terarah dalam bidang tari secara formal dan non formal.

\section{1) Pelatihan Formal}

Pelatihan formal dilakukan di berbagai macam sekolah-sekolah yang ada di sekitar Losarang, diantaranya SMAN 1 Losarang, SMAN 1 Kandanghaur dan beberapa SMA/SLTA lainnya yang ada di Kecamatan Losarang. Pelatihan tari secara formal memang diperlukan demi kelangsungan jenis materi 
JOGED

ISSN: $1858-3989$
Irayanti (UPAYA PELESTARIAN TARI TREBANG RANDU KENTIR PADA SANGGAR ASEM GEDE DESA MUNTUR KECAMATAN LOSARANG KABUPATEN INDRAMAYU-JAWA BARAT) pembelajaran pada bidang kesenian yang ada di sekolah-sekolah tersebut.

\section{2) Pelatihan Non Formal}

Pelatihan non formal diajarkan biasanya bertempat di dalam rumah Dede Jaelani dan di pelataran rumah warga terdekat dari sanggar. Pelatihan tari non formal dilaksanakan ketika jam pelajaran sekolah telah usai, biasanya pada hari senin-jum'at itu sekitar jam 15.0017.00 WIB dan jika hari libur, dilaksanakan pada jam 13.00-16.00 WIB.

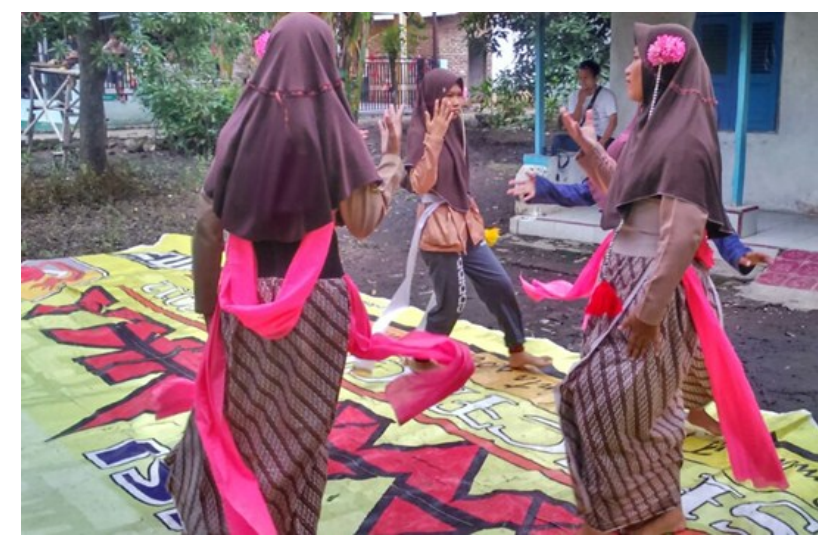

Gambar 5: Proses latihan di luar sanggar secara mandiri oleh siswi-siswi SMP. (Foto: Irayanti,2017 di Losarang)

\section{Sosialisasi}

Sosialisasi yang dilakukan Sanggar Asem Gede agar Tari Trebang Randu Kentir dikenal di masyarakat luar Indramayu maupun lingkup Jawa Barat, yaitu dengan mengikuti beberapa acara-acara budaya tertentu, seperti pada peringatan hari jadi kota Indramayu, acara-acara antar kabupaten. Tidak hanya mengikuti acara-acara di dalam maupun di luar kabupaten saja yang melibatkan Sanggar
Asem Gede yang menggelar pertunjukan Tari Trebang Randu Kentir.

Kehadiran jaringan internet yang banyak menyuguhkan berbagai macam media sosial seperti: facebook, twitter, instagram, youtube dan lain sebagainya, tampaknya dimanfaatkan dengan baik oleh Dede Jaelani. Melalui media sosial akan lebih menguntungkan dan cepat diakses oleh masyarakat luas, apalagi generasi muda sekarang selalu menggunakan internet sebagai tempat bersosialisasi.

\section{F. Hasil Pelestarian Tari Trebang Randu Kentir}

Sebuah kepedulian menghasilkan suatu aktivitas berupa tindakan atau usaha yang bersifat memperbaharui atau mengembangkanmenjadi lebih baik. Hal tersebut juga yang diingkan Sanggar Asem Gede mengenai Tari Trebang Randu Kentir agar dapat dikenal dan dapat bersaing dengan tarian lainnya. Adapun cara yang dilakukan oleh Sanggar Asem Gede yaitu dengan melakukan pelestarian terhadap Tari Trebang Randu Kentir.

Keterkaitan tersebut masih menghadirkan tatalu sebagai musik pembuka sebelum menari. Tatalu sebagai media mengumpulkan penonton, dan juga sebagai tanda pemberitahuan kepada masyarakat bahwa akan digelarkan pertunjukan Tari 
Trebang Randu Kentir. Tidak hanya tatalu yang masih dihadirkan, unsur gerak lain yang diciptakan Cahya yaitu gerak manji masih melekat pada susunan gerak Tari Trebang Randu Kentir yang ada pada Sanggar Asem Gede. Hanya saja penempatan gerak manji pada Sanggar Asem Gede, disesuaikan berdasarkan pengelompokkan latar belakang tingkat pendidikan seseorang yang ingin belajar Tari Trebang Randu Kentir.

Unsur gerak lain yang tidak ditinggalkan pada susunan gerak Tari Trebang Randu Kentir yang ada pada Sanggar Asem Gede yaitu gerak serogan. Gerak serogan menggambarkan perilaku Ki Dariwan yang berusaha menolong Nyi Dariwan yang hanyut di sungai Cimanuk.Gerak serogan juga merupakan gerak yang menjadi tema tari yang di garap Cahya dalam menyampaikan nilai dan pesan. Hasilnya, Dede Jaelani tidak menghilangkan gerak tersebut. Jika gerak serogan dihilangkan, maka tema dan nilaidi dalamnya tidak dapat mewakili apa yang ingin disampaikan pencipta tarinya (Cahya).

Tidak hanya dilihat dari aspek gerak saja yang tidak dihilangkan, tetapi iringan musiknya yakni penggunaan trebang atau blangber yang menjadi salah satu instrumen pokok yang tidak tergantikan. Kehadiran trebang diartikan sebagai alat tabuh yang menjadi ciri khas pada iringan musik Tari Trebang Randu Kentir. Jika dihilangkan, maka tarian itu tidak dinamakan Tari Trebang Randu Kentir.

Cara lain yang dimanfaatkan dengan baik oleh Sanggar Asem Gede dalam melakukan pelestarian adalah yaitu dengan memanfaatkan fitur-fitur media sosial yang disuguhkan di dunia maya (internet) sebagai proses sosialisasi. Sosialisasi diartikan sebagai cara mengenalkan sesuatu menjadi dikenal secara luas.

Hasilnya, Dede Jaelani sebagai pemilik sanggar kini selalu menggunakan media sosial untuk membagikan aktivitas sanggar. Hasil dari beberapa aspek yaitu pengembangan, pelatihan dan sosiaslisasi yang telah dilakukan Sanggar Asem Gede dalam mengenalkan Tari Trebang Randu Kentir, menghasilkan respon dari masyarakat untuk menanggap Tari Trebang Randu Kentir untuk mengisi acaraacara tertentu.

\section{PENUTUP}

Laju pertumbuhan Tari Trebang Randu Kentir semakin dikenal oleh masyarakat, tetapi dalam sajian pertunjukannnya masih dibutuhkan variasi dan perpadatan motif gerak yang menyebabkan durasi pertunjukkannya tidak padat dan cenderung membosankan untuk dilihat. Hal tersebut akhirnya direalisasikan dengan uluran tangan pemerintah Indamayu yang bekerjasama dengan Pemerintah Provinsi Jawa Barat untuk 
JOGED

ISSN: $1858-3989$
Irayanti (UPAYA PELESTARIAN TARI TREBANG RANDU KENTIR PADA SANGGAR ASEM GEDE DESA MUNTUR KECAMATAN LOSARANG KABUPATEN INDRAMAYU-JAWA BARAT) mengadakan program revitalisasi atau penghidupan kembali tentang TariTrebang Randu Kentir (2011). Tujuan program tersebut agar dapat diajarkan di sekolah-sekolah. Salah satu sanggar yang masih aktif melestarikan Tari Trebang Randu Kentir baik dalam proses pelatihan terhadap anak-anak di dalam maupun luar sekolah yaitu pada Sanggar Asem Gede (2009).

Upaya pelestarian yang dilakukan Sanggar Asem Gede yaitu dengan mengembangkan bentuk, dan membagi tingkatan materi dan susunan Tari Trebang Randu Kentir agar lebih menarik minat masyarakat untuk mempelajarinya secara bertahap. Cara yang diterapkan yaitu dengan diadakan proses pelatihan yang dilakukan secara formal dan non formal kepada anakanak sebagai generasi muda, maupun kepada masyarakat Losarang dan sekitar. Tidak hanya itu saja, kegiatan sosialisasi juga dilakukan Sanggar Asem Gede diharapkan mampu mengenalkan Tari Trebang Randu Kentir secara luas, salah satunya yaitu dengan menggunakan media sosial.

Upaya pelestarian yang dilakukan Sanggar Asem Gede dirasa belum tampak maksimal, tetapi hasil dari pelestarian yang dilakukan tampak menunjukkan peningkatan yang lebih baik setiap tahunnya (setelah revitalisasi). Hasil yang tampak secara langsung juga yakni mengenai kehadiran Tari
Trebang Randu Kentir yang kian hadir menyemarakkan perayaan maupun festivalfestival yang di gelar dari pihak pemerintah Indramayu maupun warga masyarakat Indramayu.

\section{DAFTAR SUMBER ACUAN}

\section{A. Sumber Tertulis}

Alwi, Hasan. 2005. Kamus Besar Bahasa Indonesia, edisi ketiga. Departemen Pendidikan Nasional. Jakarta: Balai Pustaka.

Bosker. 1997. Training Effectineness. Newyork, dalam Jurnal Pendidikan dan Kebudayaan oleh Khairilan Warnotodipuro. vol. 19. No 1 maret 2013. ISSN 0215-2673. Jakarta: Badan Penelitian dan Pengembangan Kementrian Pendidikan dan Kebudayaan.

Hadi, Y Sumandiyo. 2005. Sosiologi Tari: Sebuah Pengenalan Awal. Yogyakarta: Pustaka.

(Bentuk-Teknik-Isi) ketigaYogyakarta: Cipta Media.

Herdiani, Heri, Suhendi Afryanto, Endah Irawan, dkk. 2008. Mengungkap Nilai Tradisi Pada Seni Pertunjukan Jawa Barat. Bandung: Balai Pengelolaan Kepurbakalan Sejarah dan Nilai Tradisional.

Hidayat, Achmad, Dindin Rasidin, Ella Nurlaelaningsih, dkk. 1992. "Tari Randu KentirTinjauanTerhadapTari Rakyat Indramayu." Bandung: Akademi Seni Tari Indonesia. 
Sedyawati, Edi. 1981. Pertumbuhan Seni Pertunjukan. Jakarta: SinarHarapan.

Setiadi, Elly M, Kama A.HakamdanRidwan Effendi. 2009. Ilmu Sosialdan Budaya Dasar. Jakarta: Kencana.

Smith, Jacquelin Dance Composition: A practical Guide for Teacher. 1976. London: Lepus Books. Diterjemahkan oleh Ben Suharto pada tahun 1985 dengan judul Komposis iTari: Sebuah Petunjuk Praktis Bagi Guru. Yogyakarta: Ikalasti

Rustiyanti, Sri . 2010. Menyikap Seni Pertunjukan Etnik di Indonesia. Editor Endang Caturwari. Bandung: Sunan Ambu STSI Press

Warnali, Sutandi Tatang, Sulistijo, dkk. 2001. Kamus Basa Indramayu (Basa Indramayu-Indonesia).Indramayu: CV LIMA NUSANTARA.

\section{B. Narasumber}

Dede Jaelani Solichin, 34 tahun, Guru Seni Budaya SMAN 1 Losarang dan sebagai pemimpin Sanggar AsemGede.

Karna, 60 tahun, mantan panjak pada

Grup Kesenian Trebang "Randu Kentir”.

Dwi Septiani K Wulandari, 24 tahun. Alumni mahasiswa Jurusan Tari Institut Seni Budaya Indonesia (ISBI) Bandung.

\section{Discografi}

Video dokumentasi karya Seni Penyajian Tari Rakyat Jurusan Seni Tari Institut Seni Budaya Indonesia tentang Tari Trebang Randu Kentir oleh Dwi Septiani
K.Wulan dari pada tahun 28 Februari2014, koleksi pribdi Dwi Septiani K.Wulandari.

Video dokumentasi Tari Trebang Randu Kentir pada saat Sanggar Asem Gede berpartisipasi dalam acara World Dance Day 2016 di ISI Solo, video tersebut diambil oleh peneliti pada tanggal 29 April 2016.

\section{Webtografi}

http://perpustakaancyber.blogspot.co.id /2013/05/pengertian-nilai-dan-norma-sosial-dimasyarakat.html diakses pada tanggal 10 April 2017. 